\title{
Experimental investigation to limit the effecting of friction stir welding factors on the strength of AA6061-T651
}

\author{
Haider K. AL Asadi \\ Sewerage directorate, Thi-Qar province, Iraq
}

Article Info

Received Mar 14, 2019

\section{Keyword:}

Aluminium alloy

Friction stir welding

FSW, microstructure

Tensile strength

microhardness

\begin{abstract}
Properties like light weight, high strength-to-weight ratio, and good corrosion resistance make aluminium alloys widely accepted in automotive industry. The low melting point of these alloys makes welding by traditional methods difficult due to the imperfections associated with fusion processes. Friction stir welding (FSW) is a solid-state welding method invented in 1991 at the welding institute (TWI) in the UK; melting and recasting do not occur when using this process. But joints from AA6061-T651 aluminium alloy have been friction stir welded with different welding parameters like tool rotational speed and tool welding speed with constant tool dimension. The effects of rotational and welding speeds on the tensile strength, microhardness distribution and microstructure of the welding joints were studied. The results showed that the maximum tensile strength of the joints can be achieved when using tool with $18 \mathrm{~mm}$ and $5 \mathrm{~mm}$ shoulder and pin diameter at $710 \mathrm{rpm}$ tool rotational speed and $23 \mathrm{~mm} / \mathrm{min}$. Also, we observed that microhardness is markedly affected when tool rotational speed increases.
\end{abstract}

\section{Corresponding Author:}

Haider K. AL Asadi

Sewerage directorate, Thi-Qar province, Iraq

hayder.alasadi85@yahoo.com

\section{Introduction}

Welding processes are classified into two major classes: fusion without exerted forces and solid state welding with large exerted pressure [1-3]. Solid-state methods consist of a set of welding processes that produce joining by the application of pressure at a temperature less than melting points of the parent metal and filler. Friction stir welding (FSW) is one of the solid-state joining processes. FSW has been one of the most common ways for joining a wide range of lightweight materials such as aluminum and magnesium and their alloys. This process is used to avoid the fusion and solidification and defects like hot and cold cracks and high heat input when welding by conventional welding processes. Sound welds can be achieved by FSW [4, 5]. FSW has a remarkably simple concept. A non-consumable rotating tool with a specially designed pin and shoulder is plunged into the surface of the contact surfaces of two plates to be joined as shown in figure (1). The friction stirring tool consists of a shoulder and a probe (pin). When the probe contacts with the weld pieces it creates frictional and deformational heating and softens the metals of the weld pieces; heating increases when the shoulder attaches the surfaces of the weld pieces, and this results in the expansion of the softened metal zone. After the dwell time has passed, the tool begins the forward travels along the contact line of butting sheets. Fine grains are constructed behind the tool due to dynamic recrystallization. Advancing motion of the tool generates transverse loads parallel to the direction of linear motion; in addition, normal exerted force is the force required for the shoulder of tool to remain in contact with the weld piece [6-8]. 


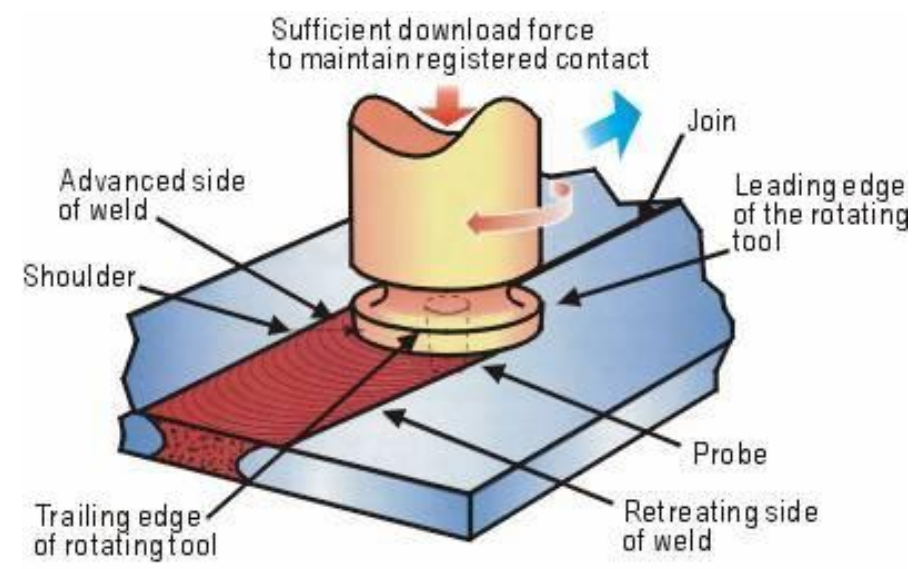

Fig. 1: Schematic diagram of the friction stir welding process [9]

Many researchers have investigated the FSW of AA6061-T651. P Srinivasa Rao et al. [10] studied the effect of tool geometrical parameters on FSW joint properties of aluminium alloy AA6061. They also studied the possibility of welding plates with a thickness of $6 \mathrm{~mm}$ from AA6061 by FSW. Different pin profiles like tapered cylindrical and square pin were used to perform the joints at three different rotational speeds (1500, 2000 , and $2500 \mathrm{rpm}$ ) with two traverse speeds of 20 and $40 \mathrm{~mm} / \mathrm{min}$. They observed that with the increase of rotation speed, the tensile properties decrease irrespective of feed rate used; furthermore, tapered pin induced lower tensile strength. S. Ravi Kumar et al. [11] investigated the effect of process parameters on the mechanical properties of FSW dissimilar joints between AA6061-T651 and AA7075-T651 alloys. Better mechanical properties (hardness and tensile strength) were achieved at tool rotational speed $900 \mathrm{rpm}$ and 100 $\mathrm{mm} / \mathrm{min}$ feeding speed with TCT tool compared to all other conditions. Fracture location was at BZ or HAZ regions. R. Madhusudh et al. [12] investigated the mechanical and microstructural properties of AA6262AA7075 dissimilar joints and found that FSW successfully produced AA6262 and AA7075, and good mechanical properties can be achieved at $1200 \mathrm{rpm}$ tool rotational speed and $0.6 \mathrm{~mm} / \mathrm{min}$ welding speed. In addition, the authors observed a noticeable variation in grain size and distribution of second phase particles $\left(\mathrm{Mg}{ }_{2} \mathrm{Si}, \mathrm{Al}_{2} \mathrm{Zn}\right)$ in TMAZ region on both AS and $\mathrm{RS}$ compared to SZ. Prince Saint et al. [13] conducted an experimental study of hardness by FSW of AA 6061-t6 and two sheets with 100x 50 x $6 \mathrm{~mm}$. The ranges of rotational speed and welding speed were 1950, 3080, $4600 \mathrm{rpm}$ with feed rate of $20,25,30 \mathrm{~mm} / \mathrm{sec}$. Increasing Brinell hardness resulted in an increase in the feeding speed at all rotational speeds. Elatharasan $e t$ al. [14] analyzed the FSW processes parameter and concluded that the parameter plays a major role in joint feature. The experiments were conducted based on three factors namely speed, feed, and axial force. The tensile strength was achieved at $96 \%$ and yield strength was $90 \%$. When there was an increase in the rotational speeds, welding speeds, and tool axial force the ultimate tensile strength of the FSW joint reached up to maximum level. Rajakumar et al. [15] studied the effect of tool parameters on the tensile strength FSW of F joints made from AA7075-T6. The results indicated that $1400 \mathrm{rpm}, 60 \mathrm{~mm} / \mathrm{min}$, and $8 \mathrm{KN}$ (axial force) with the tool dimensions of 15, $5 \mathrm{~mm}$ (shoulder and pin diameters) and $45 \mathrm{HRC}$ (tool hardness) yielded higher strength properties compared to other joints. The maximum strength properties of $315 \mathrm{MPa}$ yield strength, 373 $\mathrm{MPa}$ of tensile strength, $397 \mathrm{MPa}$ of notch tensile strength, $203 \mathrm{HV}$ of hardness and $77 \%$ of joint efficiency were attained, respectively for the joint fabricated using above processes and tool parameters. Defect-free and fine-grained microstructure of weld nugget and uniformly distributed finer MgZn2 particles in the weld nugget are found to be the important factors responsible for the higher tensile strength of the above joint. P. Raja et al. [16] produced the FSW of AA6061 both cast and wrought alloys. They observed that the strength and hardness are gradually increased at $1200 \mathrm{rpm}$ and the efficiency of joining reached $94 \%$. Mustafa et al. [17] analysed the effect of processing parameters on the mechanical and metallurgical properties of dissimilar joints of AA6082-AA6061 produced by FSW. Different FSW samples were produced by changing the welding speeds as 50 and $62 \mathrm{~mm} / \mathrm{min}$ and by changing the alloy positioned on the advancing side of the tool. In all the experiments the rotating speed was fixed at $1600 \mathrm{rpm}$. It was observed that the downward force was constant as the welding speed for all the produced joints increased. The tensile strength of the dissimilar joint was lower than that of the base metal. With the 6082 alloy positioned on the advancing side of the tool, the 
dissimilar joints exhibited good mechanical properties with respect to AA6061. Nabeel Gharaibeh et al. [18] and Sefika Kasman et al. [19] also studied the FSW of dissimilar materials.

This paper included a practical comparison between the mechanical properties and the microscopic structure of similar FSW welding joints from AA6061- T651 fabricated at different ranges of tool rotational speed (TRS) and welding speed or feeding speed (FS). Cylindrical pin tool type made from H13 steel was used. Other parameters such as tilt angle, plunging depth, and axial force remained constant. Zero angles were used as the tilt angles; there are few studies which used this value to perform FSW joints. Many tests were used to predict the best process parameters like ultimate tensile strength (UTS) test, microhardness test, and microstructure. The main aims of this study include:

1. Demonstrate and investigate the most important parameters that affect the butt joint of 6061-T651 aluminium alloy with $6 \mathrm{~mm}$ thickness using FSW process.

2. Estimate the best parameters that lead to maximum ultimate tensile strength at different tool rotating speeds and feeding speeds with fixing all of tilt angle, plunge depth, plunge rate, exerted force, and tool geometry.

\section{Experimental work}

Sheets from aluminium alloys of AA6061-T651 with $6 \mathrm{~mm}$ thickness were selected to fabricate similar butt joints using the FSW process; where T651 indicate to heat treatment consists of solution heat treated, stretched and artificially aged butt joints consisting of two symmetrical pieces with dimensions 100x 50x 6 $\mathrm{mm}$ were cut from the sheets using a milling machine. Figure (2) shows the butt joint. Standard chemical composition and chemical analysis were conducted in a specialized institute of engineering industries for the aluminium alloy. According to the examination certificate number 122 and as represented in the table (1), the test was conducted at $21.5^{\circ} \mathrm{C}$ with $41 \%$ humidity.

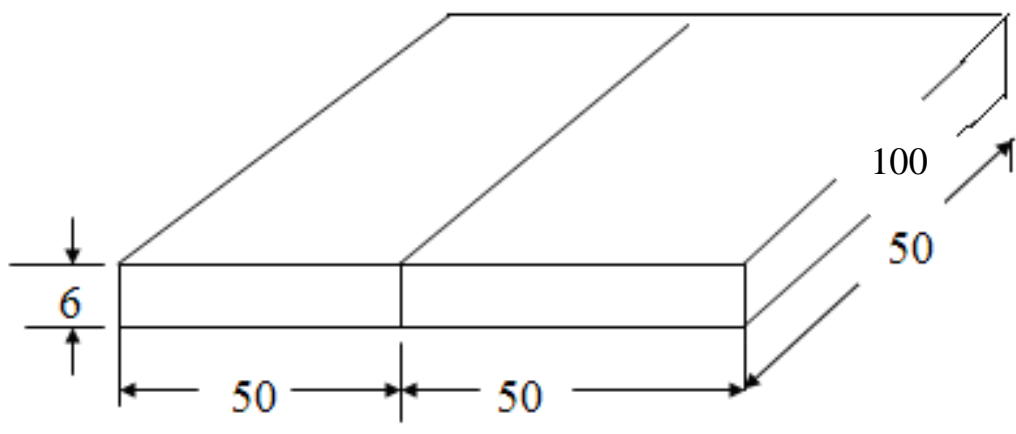

Fig. 2: Butt joint design

Table (1): Standard and real chemical analysis

\begin{tabular}{l|lllllllllll}
\hline \multicolumn{2}{l}{ Component } & $\mathrm{Si}$ & $\mathrm{Fe}$ & $\mathrm{Cu}$ & $\mathrm{Mn}$ & $\mathrm{Mg}$ & $\mathrm{Cr}$ & $\mathrm{Ni}$ & $\mathrm{Zn}$ & $\mathrm{Ti}$ & $\mathrm{Al}$ \\
\hline \multirow{3}{*}{} & stand & 0.8 & 0.7 & 0.4 & 0.15 & 1.2 & 0.35 & & 0.25 & & Rem \\
\cline { 2 - 11 } & real & 0.637 & 0.509 & 0.238 & 0.88 & 0.937 & 0.163 & 0.003 & 0.015 & 0.05 & $\mathrm{~B}$ \\
\hline
\end{tabular}

Several important preparatory processes have been conducted on the welding pieces before FSW welding process, like levelling and grinding of the contact surfaces and cleaning the surfaces of weld pieces to achieve complete contact between faying surfaces along with welding line.

\section{Tool design}

Conventional design was used to manufacture the FSW processes. Tools were made from rod with $32 \mathrm{~mm}$ diameter of $\mathrm{H} 13$ tool steel by turning on the lathe machine. Table (2) represents the chemical composition of H13. AISI H13 is a chromium-molybdenum-vanadium alloyed steel. This tool consists of two significant parts: the shoulder which is responsible for generating the bulk of the heat necessary to soften the metal, and 
the pin which is responsible for circulating plasticized metal surrounding its surface. The dimensions of FSW tool were $18 \mathrm{~mm}$ and $5 \mathrm{~mm}$ diameter (shoulder (Ds) and pin (DP)), respectively; other dimensions are shown in figure (3). FSW tool was heat treated for getting 50-55HRC.

Table (2): Typical analysis of H13 tool steel

\begin{tabular}{lllllll}
\hline Alloying element & $\mathrm{C}$ & $\mathrm{Si}$ & $\mathrm{Mn}$ & $\mathrm{Cr}$ & $\mathrm{Mo}$ & $\mathrm{V}$ \\
\hline $\mathrm{Wt} \%$ & 0.39 & 1 & 0.4 & 5.3 & 1.3 & 0.9 \\
\hline
\end{tabular}

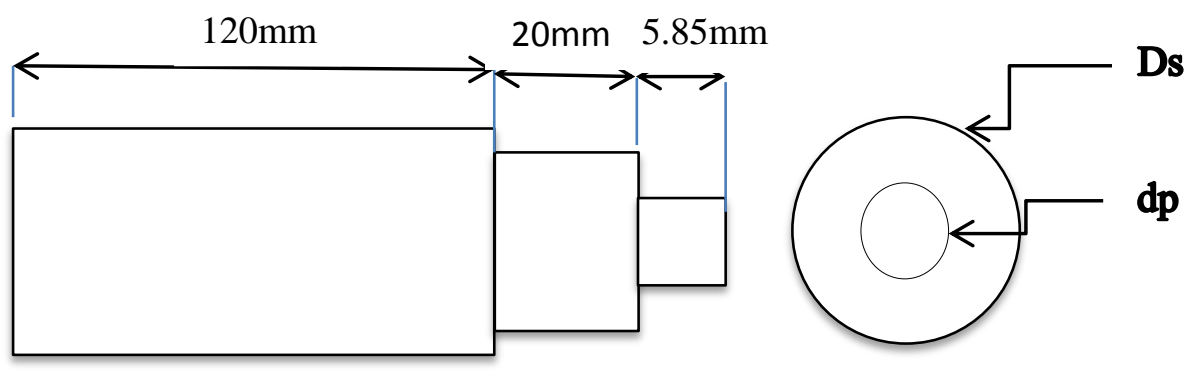

Fig.3: FSW tool

\section{Welding machine}

Conventional vertical milling machine was used as FSW welding machine. The rotational speed of spindle could be changed by setting the control panel of the machine. Figure (4) represents the machine used as FSW machine in this study. Three rotational speeds and three traveling speeds were used to determine the best rotational and travers speeds for four designed tools. In addition, they were used to investigate the effect of these parameters on the mechanical properties of the weld joints. Table (3) represents FSW parameters.

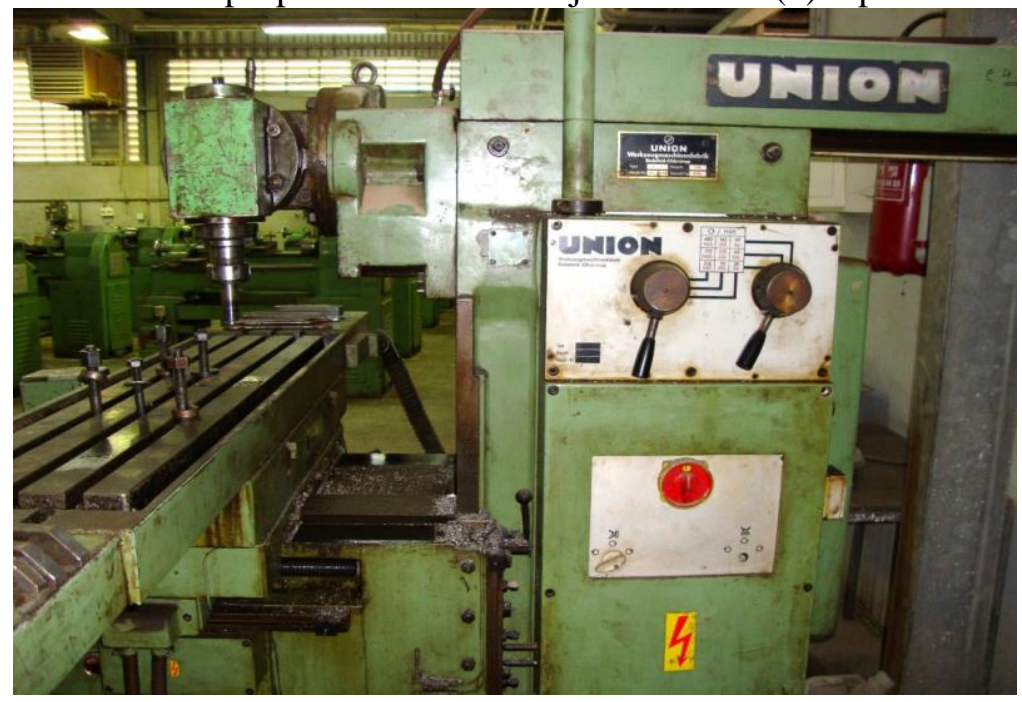

Figure (3) FSW machine

Table (3): FSW parameters

\begin{tabular}{ccc}
\hline Parameter & Values & Sample no \\
\hline TRS $(\mathrm{rpm})$ & $710,960,1400$ & \\
FS $(\mathrm{mm} / \mathrm{min})$ & $23,36,42$ & \\
Ds $(\mathrm{mm})$ & 18 & \\
dp $(\mathrm{mm})$ & 5 & \\
Tilt angle $(\mathrm{deg})$ & 0 & \\
\hline
\end{tabular}




\section{Welding procedures}

The welding procedures consisted of fixing the welding specimens in the fixture arrangement on the table of machine, setting the machine to determine the rotational and travers speed through locating the tool at the start point of the weld joint (about $15 \mathrm{~mm}$ from the front edge), and rotating the tool at the selected speed. The TRS ranges were 710, 960, $1400 \mathrm{rpm}$ and the FS ranges were 23, 36, $42 \mathrm{~mm} / \mathrm{min}$.

Plunging stage: in this stage, $0.1 \mathrm{~mm}$ of feeler gauge blade was used to adjust the plunge depth. Then, the probe of rotating tool plunged into the surface of the weld joint until the face of the shoulder touched the surface of weld pieces; then, plunging continued until the shoulder immersion depth reached $0.15 \mathrm{~mm}$ with 30 sec dwell time. This time was enough to soften and stir the metal. Welding step: immediately after metal softening and stirring, the machine table moved forward with its certain linear speed $(\mathrm{mm} / \mathrm{min})$ to make FSW. Pull off step: in this step, the machine table stopped, and tool retracted after the FSW line finished. Figure (4) shows some of the welding stages.

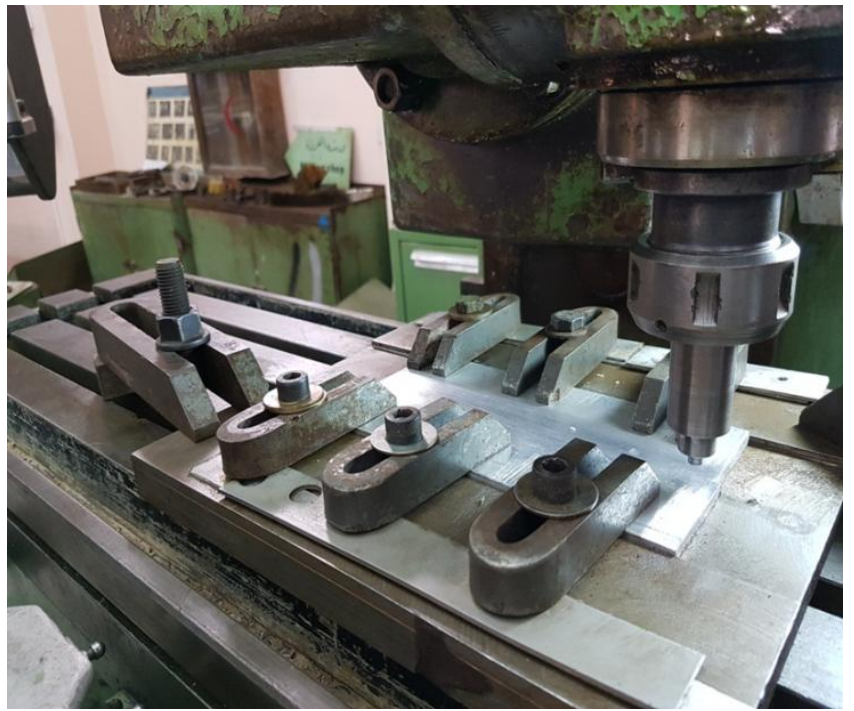

a

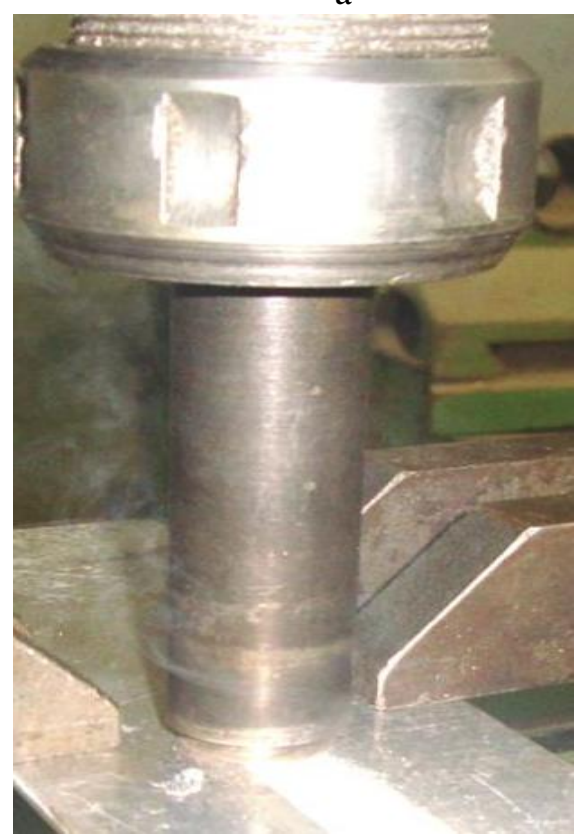

c

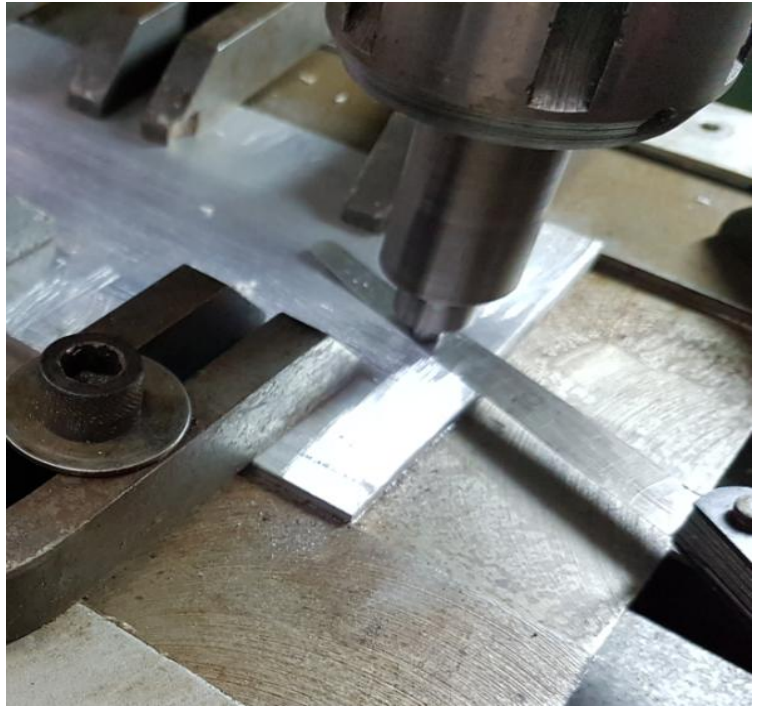

$\mathrm{b}$

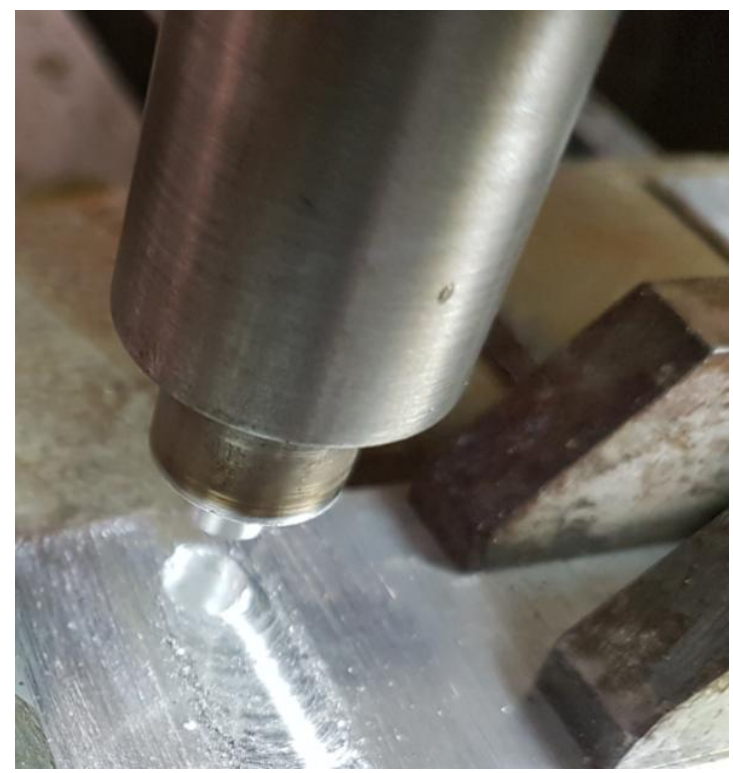

d

Fig. 4: Welding procedures (a) fixing stage, (b) using feeler gauge, (c) welding stage and (d) pull off stage 


\section{Tests}

The tensile test specimens were prepared using milling machining and according to ASTM E8M standards as shown in figure (5). $25 \mathrm{KN}$, computer controlled universal testing machine (UTM). Three samples were used to find the average of ultimate tensile strength (UTS) from each welding joint. All specimens were cut perpendicularly on the welding line. Light optical microscope was used to achieve the macro and micro structural examinations. The specimens for metallographic examinations were sectioned to the required dimension from the joint comprising stirred zone (SZ), thermo mechanically affected zone (TMAZ), and base metal (BM) regions and were polished using different grit size of Sic papers. Final polishing was done using the diamond paste on the disc polishing machine. Specimens were etched with emersion in the fresh Keller's reagent with composition of $5 \mathrm{ml} \mathrm{HNO}_{3}, 3 \mathrm{ml} \mathrm{HCl}, 2 \mathrm{ml} \mathrm{HF}$, and $190 \mathrm{ml} \mathrm{H}_{2} \mathrm{O}$ for 10-30 sec to reveal the macro- and microstructures. Hardness testing was carried out using Vickers pyramid hardness testing machine with a load of $1000 \mathrm{gf}$ divided into eight steps. Hardness survey was conducted along with straight line vertically on the welding line with $1 \mathrm{~mm}$ regular interval from the centre of weld as shown in figure (6).

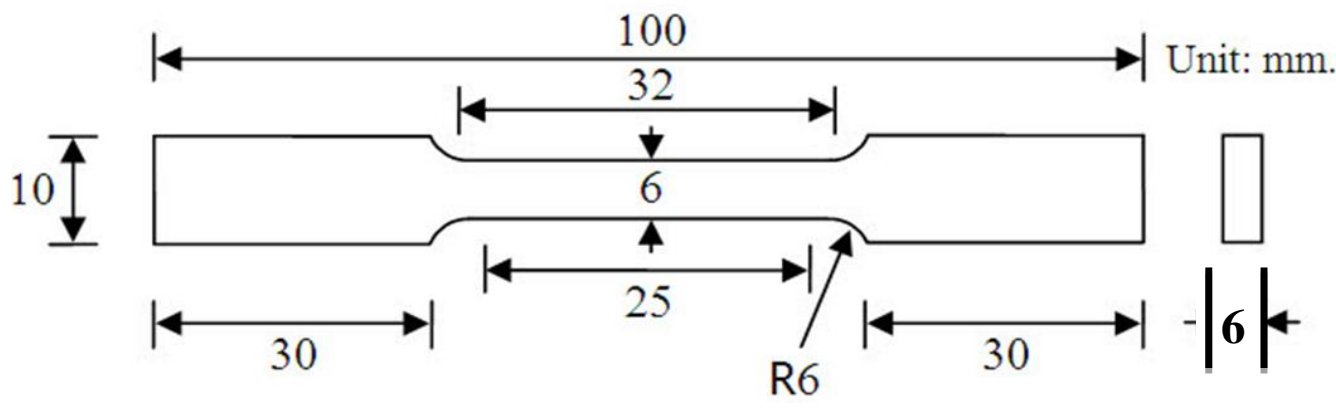

Fig.5: Tensile test specimen as per ASTM E8M [20]

\section{Results and discussion}

The average tensile test results of three samples were prepared from AA6061- T651 base metal (326.128 $\mathrm{MPa}$ ), which was a little higher than standard value due to the tensile test sample preparation. Table (4) represents the tensile test results.

Table (4): Tensile test results

\begin{tabular}{|c|c|c|c|c|c|c|c|}
\hline \multirow[t]{2}{*}{ No } & \multirow{2}{*}{$\begin{array}{l}\text { Tool dimension } \\
\text { in } \mathrm{mm}\end{array}$} & \multirow[t]{2}{*}{ TRS in rpm } & \multirow{2}{*}{$\begin{array}{l}\text { FS in } \\
\mathrm{mm} / \mathrm{min}\end{array}$} & \multicolumn{3}{|c|}{ Ultimate tensile strength in $\mathrm{MPa}$} & \multirow{2}{*}{$\begin{array}{c}\text { Average } \\
\text { UTS in } \\
\text { MPa }\end{array}$} \\
\hline & & & & Sample 1 & Sample 2 & Sample 3 & \\
\hline $1-$ & \multirow{9}{*}{$\begin{array}{c}\text { Ds }=18 \mathrm{~mm} \\
\mathrm{dp}=5 \mathrm{~mm}\end{array}$} & \multirow[t]{3}{*}{710} & 23 & 215.83 & 241.3 & 254.97 & 237.37 \\
\hline $2-$ & & & 36 & 185.07 & 185.28 & 218.069 & 196.14 \\
\hline $3-$ & & & 42 & 159.544 & 181.15 & 159.011 & 166.568 \\
\hline 4- & & \multirow[t]{3}{*}{960} & 23 & 222.23 & 189.95 & 199.63 & 203.95 \\
\hline $5-$ & & & 36 & 130.82 & 128.47 & 124.46 & 128.58 \\
\hline 6- & & & 42 & 99.23 & 119.24 & 127.4 & 106.42 \\
\hline 7- & & \multirow[t]{3}{*}{1400} & 23 & 170.8 & 140.7 & 165.56 & 159.02 \\
\hline 8- & & & 36 & 160.12 & 166.92 & 185.19 & 170.74 \\
\hline 9- & & & 42 & 94.41 & 102.19 & 90.34 & 95.65 \\
\hline
\end{tabular}




\subsection{Effect of tool rotational speed (TRS)}

As table (4) reveals, UTS is decreased when the tool rotational speed (TRS) is increased. Maximum UTS is achieved at $710 \mathrm{rpm}$ and $23 \mathrm{~mm} / \mathrm{min}$ and equal $237.37 \mathrm{MPa}$. This value is equal to $72.81 \%$ from the base metal strength. The increase in the UTS can be attributed to generating appropriate heat and sufficient plastic flow from advancing side (AS) to retreating side (RS). A proper mixing in the SZ region tends to a good dynamic recrystallization which, in turn, leads to produce fine grains in this zone and good distribution of intermetallic particles. Grain softening and correct distribution of intermetallic particles play a major role in the strengthening by increasing each UTS and hardness of weld joint. Minimum UTS was at $1400 \mathrm{rpm}$ and 42 $\mathrm{mm} / \mathrm{min}$ because higher heat input and slower rate of cooling in FSW region can lead to excessive growth in grain structure and bad distribution of second phase particles which, in turn, lower the ultimate tensile strength especially at high welding speed. Figure (6) represents the effect of tool rotational on the max UTS at different welding speed FSW.

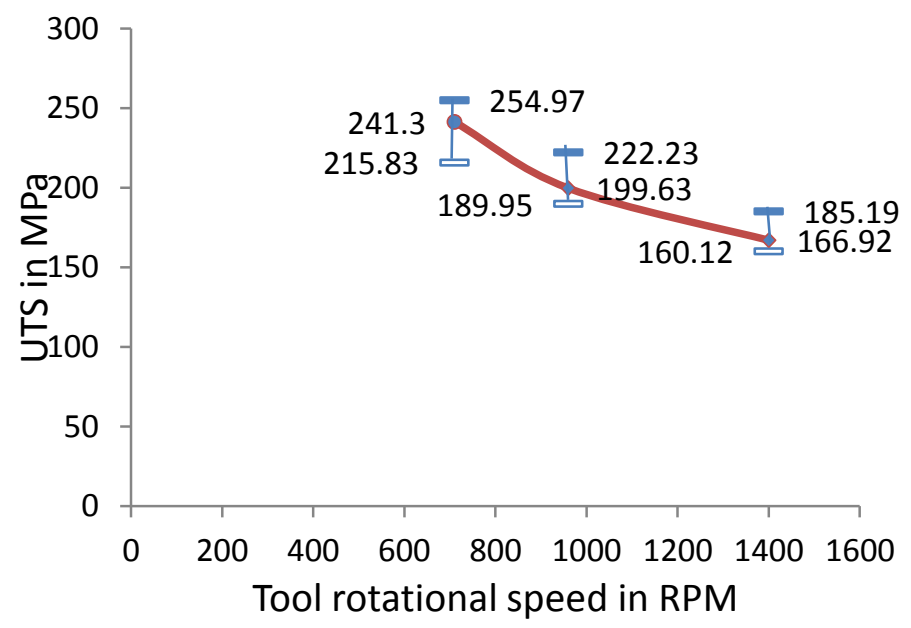

Fig (6): The effect of tool rotational speed on the max ultimate tensile strength

\section{Microstructure evolution}

Four different zones can be distinguished from microstructural examination: (1) stirring zone (SZ) that surrounds the pin of tool and has fine and equated grain structure due to dynamic recrystallization, (2) thermal mechanical zone (TMAZ) which is the second region in the vicinity of the SZ region and has elongated and dynamic recuperated grain structure, (3) heat effected zone (HAZ) is the third zone, and (4) BM which has no affected structure and has the original rolled grain structure. Figure (7) illustrates the optical micrograph in FSW weld area. Figure (8) shows the microstructure regions of weld joint produced by $(\mathrm{Ds}=18 \mathrm{~mm}, \mathrm{dp}=5 \mathrm{~mm})$ tool at TRS $(710 \mathrm{rpm})$ and FS $(23 \mathrm{~mm} / \mathrm{min})$. SZ region exhibits fine and equated grains structure due to dynamic recrystallization and good distribution of second phase particles.

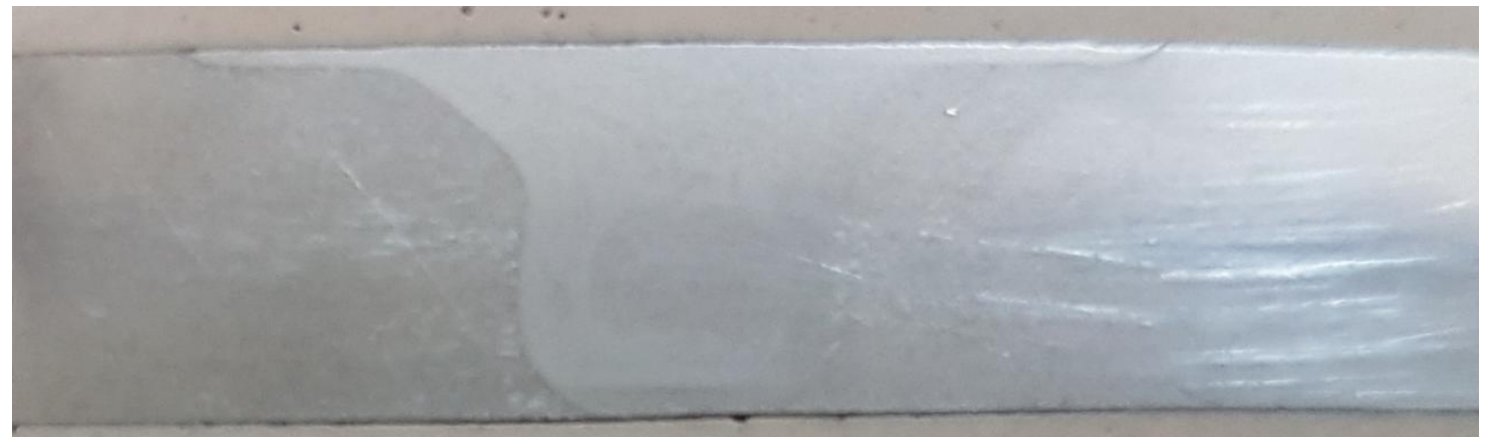

Fig.7: The optical micrograph of FSW weld area 
Core grains of intermetallic

Fine grains of intermetallic

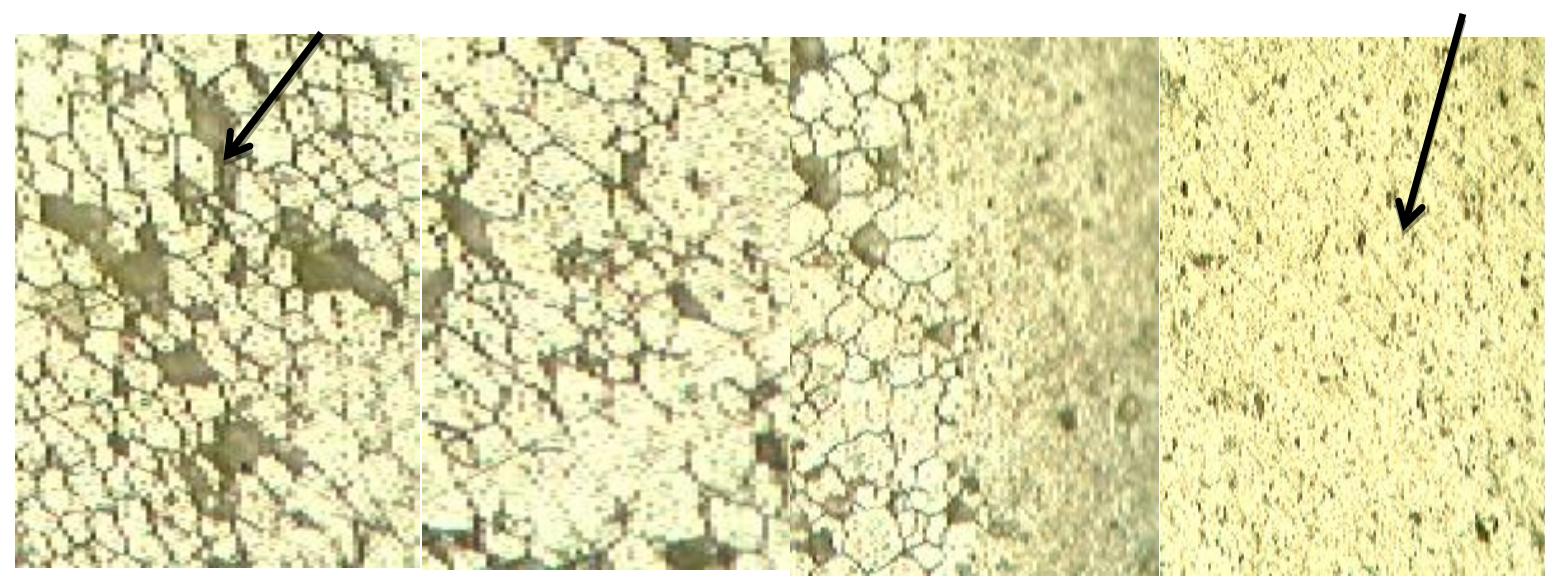

Fig (8): Microstructure zones of joint produced by (18 -5) $\mathrm{mm}$ at $710 \mathrm{rpm}$ and $23 \mathrm{~mm} / \mathrm{min}, 40 \mathrm{X}$.

Microstructure of welding zones is clearly affected with TRS due to content of heat generation. High tool rotation speed and low welding speed tend to more heat input into welding zones which in turn lead to grain growth; this can be clearly seen in figure (9).
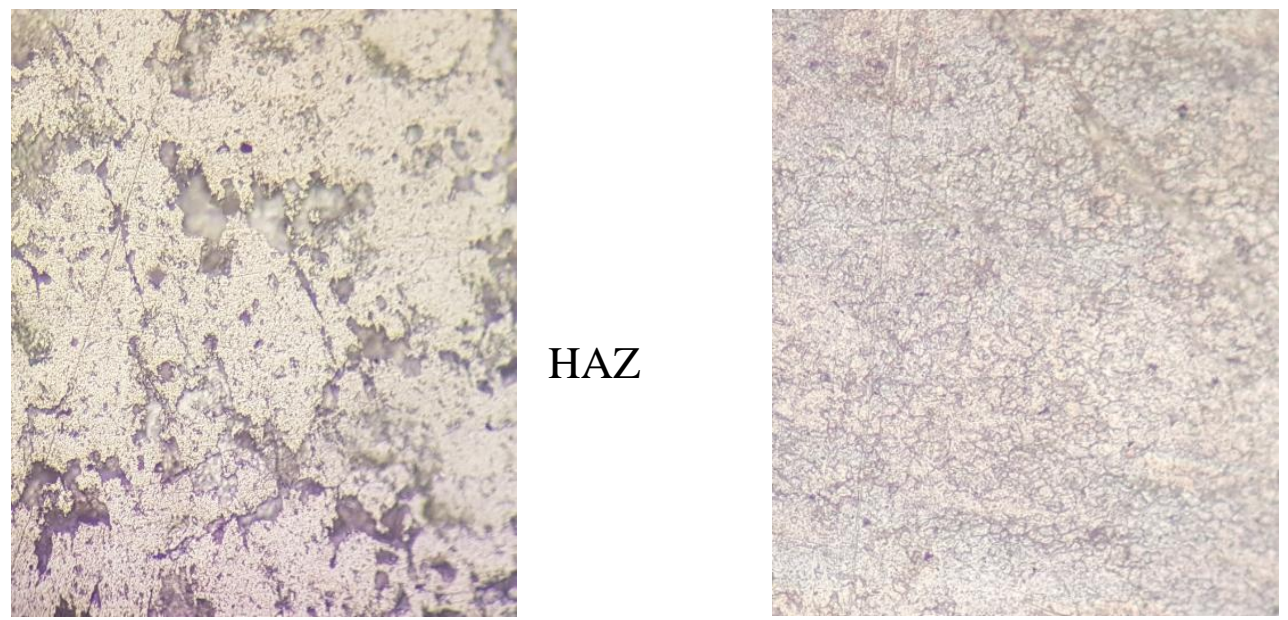

Fig.9: Microstructure images of SZ and HAZ of (1400 rpm -23mm/min) made by (18- 5) $\mathrm{mm}$ tool 40X

\subsection{Micro hardness variation}

Figure (10) illustrates the variation of microhardness with different TRSs. From profile of hardness, a gradual increase can be seen in the Vickers micro hardness toward the center of the weld, especially in the (SZ). This happens because of the grain structure which consists of very fine grains produced due to highly plastic deformation, which is increased when the rotational tool speed increases from $710 \mathrm{rpm}$ to $1400 \mathrm{rpm}$. Fine grains mean more grain boundaries. One of the strengthening mechanisms is that these boundaries act as barriers for dislocation moving. Fine grains lead to high dislocation density and then increase the strength of this region. More grain boundaries result in increasing the dislocation of pile up points, and these tend to increase the strength and hardness. Also, the strength of AA 6061 is attributed to predominantly coherent phase $\left(\beta^{\prime \prime}-\mathrm{Mg}_{2} \mathrm{si}\right)$ with a needle-shaped precipitate. From the SZ microstructure, the precipitates' density decreased as a result of higher heat input into this zone during thermal cycle which tend to dissolve some of the fine needle-shaped particles in the aluminum matrix, and the particles re-precipitate as spherical shapes. These particles play a major role in pinning the motion of dislocations. 


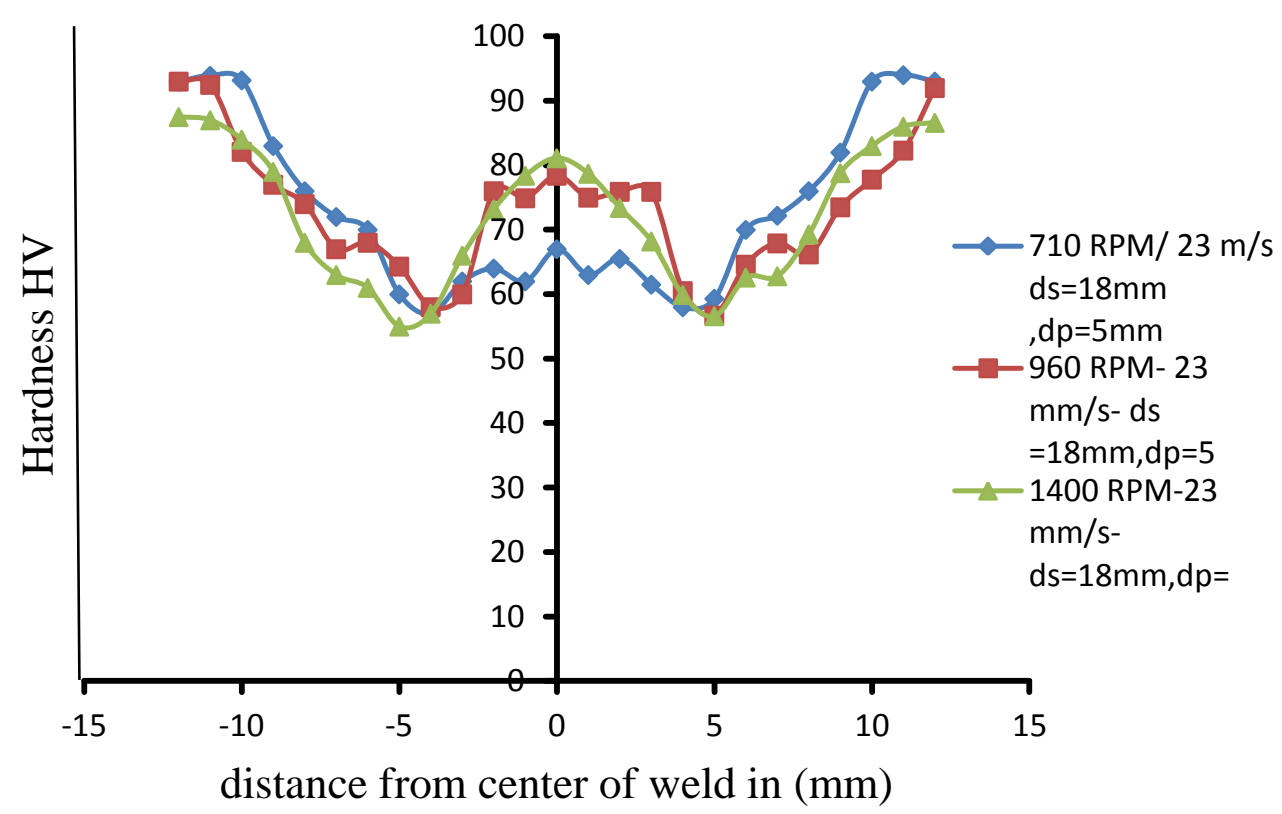

Fig (10): The profile of microhardness represents the variation of micro-hardness with rotational tool speed.

\section{Conclusions}

1. The FSW method used successfully to join similar aluminium alloys (AA6061-T651).

2. Better mechanical properties (ultimate tensile strength and hardness) can be investigated in the FSW when using $710 \mathrm{rpm}$ as the TRS and $23 \mathrm{~mm} / \mathrm{min}$ with $(18,5) \mathrm{mm}$ tool.

3. Microstructure examinations revealed four distinct zones: stirred zone (SZ) with a fine-grain structure which gives it high strength compared with heat affected zone (HAZ), thermo mechanical zone (TMAZ), and base metal (BZ).

4. The breadth of HAZ depends on the TRS.

5. The profile of microhardness indicates that the hardness is increased in the SZ as the TRS increases due to the increase in strain hardening and refining the second phase particles. Also, the curve shows a decrease in micro hardness at HAZ when TRS increases as the result of higher heat.

\section{Acknowledgement}

All FSW procedures and related tests were performed at the workshops and laboratories of the Department of Mechanical Engineering, Collage of Engineering, Thi-Qar University, Iraq. The author would like to thank all the staff for their kind support especially, Falih Alazawi and Jaber Alkhfajy.

\section{References}

[1] M. K. Abbass, S. K. Hussein and A. A. Khudhair, "Optimization of Mechanical Properties of Friction Stir Spot Welded Joints for Dissimilar Aluminum Alloys (AA2024-T3 and AA 5754-H114)," Arabian Journal for Science and Engineering, vol. 41, (11), pp. 4563-4572, 2016.

[2] T. Hsu, L. Wu and M. Tsai, "Resistance and friction stir spot welding of dual-phase (DP 780) - a comparative study," The International Journal of Advanced Manufacturing Technology, vol. 97, (5), pp. 2293-2299, 2018.

[3] H. Sidhar et al, "Friction stir welding of Al-Mg-Li 1424 alloy," Materials \& Design, vol. 106, pp. 146$152,2016$.

[4] B. Durakovic and H. Basic, "Continuous Quality Improvement in Textile Processing by Statistical Process Control Tools: A Case Study of Medium-Sized Company," Periodicals of Engineering and Natural Sciences, vol. 1, no. 1, pp. 39-46, 2013.

[5] B. Durakovic, "Design for Additive Manufacturing: Benefits, Trends and Challenges," Periodicals of Engineering and Natural Sciences, vol. 6, no. 2, pp. 179-191, 2018. 
[6] K. Gangwar and M. Ramulu, "Friction stir welding of titanium alloys: A review," Materials \& Design, vol. 141, pp. 230-255, 2018.

[7] N. Dialami et al, "Enhanced friction model for Friction Stir Welding (FSW) analysis: Simulation and experimental validation," International Journal of Mechanical Sciences, vol. 133, pp. 555-567, 2017.

[8] A. C. F. Silva et al, "Temperature measurements during friction stir welding," The International Journal of Advanced Manufacturing Technology, vol. 88, (9), pp. 2899-2908, 2017.

[9] E. Hoyos, D. López and H. Alvarez, "A phenomenologically based material flow model for friction stir welding," Materials \& Design, vol. 111, pp. 321-330, 2016.

[10] W. D. P. Brassington and P. A. Colegrove, "Alternative friction stir welding technology for titanium-6Al$4 \mathrm{~V}$ propellant tanks within the space industry," Science and Technology of Welding and Joining, vol. 22, (4), pp. 300-318, 2017.

[11] I. Kalemba-Rec et al, "Effect of process parameters on mechanical properties of friction stir welded dissimilar 7075-T651 and 5083-H111 aluminum alloys," The International Journal of Advanced Manufacturing Technology, vol. 97, (5), pp. 2767-2779, 2018.

[12] K. S. Anil Kumar, S. M. Murigendrappa and H. Kumar, "Experimental investigation on effects of varying volume fractions of $\mathrm{SiC}$ nanoparticle reinforcement on microstructure and mechanical properties in friction-stir-welded dissimilar joints of AA2024-T351 and AA7075-T651," Journal of Materials Research, vol. 34, (7), pp. 1229-1247, 2019.

[13] M. M. Hasan, M. Ishak and M. R. M. Rejab, "Effect of pin tool flute radius on the material flow and tensile properties of dissimilar friction stir welded aluminum alloys," The International Journal of Advanced Manufacturing Technology, vol. 98, (9-12), pp. 2747-2758, 2018.

[14] E. Radhakrishnan et al, "Strength and hardness studies of C44300 tube to AA7075-T651 tube plate threaded and unthreaded dissimilar joints fabricated by friction welding process," Journal of Materials Research and Technology, vol. 8, (4), pp. 3424-3433, 2019.

[15] De Filippis, Luigi Alberto Ciro et al, "Optimization and Characterization of the Friction Stir Welded Sheets of AA 5754-H111: Monitoring of the Quality of Joints with Thermographic Techniques," Materials (Basel, Switzerland), vol. 10, (10), pp. 1165, 2017.

[16] P. Wu et al, "A Study on Dissimilar Friction Stir Welded between the $\mathrm{Al}^{-} \mathrm{Li}^{-} \mathrm{Cu}$ and the $\mathrm{Al}^{-} \mathrm{Zn}^{-} \mathrm{Mg}^{-} \mathrm{Cu}$ Alloys," Materials (Basel, Switzerland), vol. 11, (7), pp. 1132, 2018.

[17] M. K. Abbass, S. K. Hussein and A. A. Khudhair, "Optimization of Mechanical Properties of Friction Stir Spot Welded Joints for Dissimilar Aluminum Alloys (AA2024-T3 and AA 5754-H114)," Arabian Journal for Science and Engineering, vol. 41, (11), pp. 4563-4572, 2016.

[18] R. Singh et al, "Experimental investigations for mechanical and metallurgical properties of friction stir welded recycled dissimilar polymer materials with metal powder reinforcement," Composites Part B, vol. 103, pp. 90-97, 2016.

[19] M. GULBUDAK and Y. BOZKURT, "The effect of process parameters on the material position of dissimilar friction stir welded AA2024-T3/5754-H22 joints," Metallic Materials, vol. 55, (1), pp. 21-32, 2017.

[20] G. Peng et al, "Effect of Forced Air Cooling on the Microstructures, Tensile Strength, and Hardness Distribution of Dissimilar Friction Stir Welded AA5A06-AA6061 Joints," Metals, vol. 9, (3), pp. 304, 2019. 